\title{
Loss and Rebuilding of Local Government's Credibility in Public Emergencies - Take the COVID-19 Epidemic as an Example
}

\author{
Xiaoning $\mathrm{Zhu}^{1, \text { a }}$, Haimei Zhou ${ }^{1, \mathrm{~b}, \text { * }}$ \\ ${ }^{1}$ School of Public Management, University of Electronic Science and Technology of China, Chengdu, Sichuan, 10064, \\ China \\ azhuxn1956@163.com, ${ }^{b}$ Meir96@163.com
}

\begin{abstract}
Public emergencies and the credibility of local governments promote and restrict each other. Local government will gain greater credibility if it handles emergencies well, and local government credibility is the main barrier when facing public emergencies. Good credibility can enable local governments to gain more support and trust from the public when dealing with public emergencies. The frequent occurrence of public incidents makes the credibility of local governments face severe challenges at present. Therefore, this article takes the COVID-19 epidemic as an example to study how to rebuild the credibility of local governments in public emergencies.
\end{abstract}

Keywords: public emergency, local government, credibility

\section{INTRODUCTION}

Public emergencies have occurred frequently in recent years, which have caused different degrees of damage to people's production, life, and property safety. With the rapid transformation of China's society, citizens' access to information in the Internet environment has been diversified, and the ability to acquire information has been continuously enhanced. Public emergencies have been rapidly spread under Internet technology, causing social harm and easily to cause public crisis. As the main body of public emergency management, local governments will assume the main responsibility for handling public emergency in the event of a public emergency. [1] The local government's response to public emergencies and measures taken in the first place have caused the local government's credibility to face a severe test.[2] Therefore, further research on how to rebuild the credibility of local governments in public emergencies has important theoretical and practical significance.

\section{PUBLIC EMERGENCY AND GOVERNMENT CREDIBILITY}

At present, the definition of public emergencies in academic circles is still controversial. Because public emergencies are usually suddenly and highly destructive, therefore, this article defines an public emergency as an emergency that occurs suddenly, seriously affects the normal operation of society, and poses a threat to life, property, and the environment. The latest public health emergency COVID-19 broke out in Wuhan at the end of 2019, and the epidemic has spread rapidly. It was designated by the World Health Organization (WHO) as an "public health emergency of international concern". The epidemic has brought severe challenges to the economic development and social stability of the country and the world. After the epidemic broke out, the Wuhan Municipal Government took measures to control the epidemic quickly, but the lack of experience in responding to public emergencies caused public dissatisfaction and seriously challenged the credibility of local governments.

Government credibility is the public's trust in the government and its administrative actions (Nanke Ye, 2011). [3] This article considers that government credibility is the public's subjective evaluation of the government's performance of its responsibilities, and reflects the public's trust and satisfaction with the government. The level of government credibility depends on the public's attitude towards government administrative behavior: one is the degree of public trust in the government, and the other is the degree of public satisfaction with government services.

Public emergencies and the credibility of local governments promote and restrict each other. [4] Local government will gain greater credibility if it handles emergencies well, and local government credibility is the main barrier when facing public emergencies. Good credibility can enable local governments to gain more support and trust from the public when dealing with public emergencies. It can be said that the two are mutually reinforcing and restricting each other. Therefore, it is necessary to clarify the relationship between public emergencies and the credibility of local governments. 


\section{ANALYSIS OF THE RELATIONSHIP BETWEEN PUBLIC EMERGENCIES AND THE CREDIBILITY OF LOCAL GOVERNMENTS}

\subsection{Public emergency affects the credibility of local government}

The attitude and behavior of local government in dealing with public emergencies will affect its credibility. First of all, as the main body of public emergency management, local government should assume the main responsibility of dealing with public emergency. Safeguarding public interest is the value pursuit of local governments in dealing with public emergencies. If the local government always acts in the public's interest, the public will recognize the local government's behavior and act according to its will. On the contrary, the government's behavior will be questioned by the public, which will cause a crisis of public trust in the government and lead to the decline of local government's credibility. Secondly, the actual actions of local governments directly affect the public's evaluation of the government, thus affecting the credibility of local governments. The governing concept and administrative ability advocated by local governments can be fully displayed in public in public emergencies, which is a good opportunity for the public to know the local government, thus forming or strengthening the public's evaluation on the trust or distrust of local government. In addition, the effectiveness of local governments in dealing with public emergencies will also affect their credibility. Government credibility $=$ government administrative ability $\times$ public satisfaction (Tiehan Tang, 2005). [5] From the formula, government credibility is the objective result of administrative ability. The administrative ability of local governments can be demonstrated by their effect in dealing with public emergencies. If local governments can quickly and effectively control the spread of the crisis and stop the losses in time, they will help win public recognition and enhance their credibility.

\subsection{The credibility of local government affects the handling effect of public emergencies}

The credibility of local government determines their ability to deal with public emergencies. Relying solely on the government's strength, it is difficult to deal with the crisis quickly, which requires the assistance and cooperation of the public and social forces to form a good interaction. The government's credibility plays an important role. To be specific, good government credibility enables the public to recognize and respond positively to the government's policies and work actively. Secondly, it can attract more social organizations and individuals to participate in the handling of public emergencies. The higher the credibility of the local government, the more sincerely the social organizations and individuals can cooperate with the government to cope with the crisis. [6] Finally, good local government credibility is conducive to maintaining social stability. As a kind of social capital, government credibility has become a bridge between the government and the public. [7] When the local government has good credibility, the public has a high degree of trust in it. In public emergencies, the government's actions will be understood and supported by the public, thus eliminating the panic and dissatisfaction. It can be said that the credibility of local government is the cornerstone of public stability and social order.

\section{LOSS AND ENDANGERMENT OF LOCAL GOVERNMENT CREDIBILITY IN PUBLIC EMERGENCIES}

Questioning local government governance is a sign of a loss of credibilityIn responding to public emergencies, some local governments tried to cover up and conceal the truth of the incident after the crisis due to their own interests or political performance considerations, causing strong public dissatisfaction. And due to the lack of supervision, the government's governing behavior has been biased, and the ability of local governments to respond to the crisis has been questioned. Facing the outbreak of the COVID-19, the Wuhan Municipal Government quickly took measures to establish isolation hospital. But hospitals are overwhelmed by the increasing number of confirmed cases. As a result, many patients could not be effectively rescued in the early stage of the epidemic, which caused the public to question the epidemic response measures of the Wuhan Municipal Government. The subsequent outbreak of the Hubei Red Cross Society's epidemic prevention material distribution incident kept the public questioning, leading to the public's epidemic of the government. Distrust of prevention and control capabilities One of the dangers of the loss of local government credibility is the rumors that have caused social panic. The public is prone to develop anxiety and nervousness in public emergencies, and generates a strong demand for accurate information.[8] It is difficult for the public to judge its accuracy in the face of huge amounts of information. At this time, the public is eager to obtain accurate information from authoritative departments such as the government. When the local government fails to release the information at the first time or the information released is inaccurate, it is easy to form a rumor crisis and cause panic. In the COVID-19 epidemic, although the Wuhan Municipal Government held a press conference as soon as possible to announce the relevant information of the epidemic. Due to the discrepancy between the information published in previous conferences and the actual situation, the public has questioned the accuracy of the information released. Once the authority of the government is challenged, various rumors will arise, which is not conducive to the effective control of the epidemic. The second is a crisis of public trust in local 
responsibility of some staff members, phenomena such as absenteeism and concealment of information were reported during the epidemic prevention and control work. This has seriously damaged the image of local governments in the public mind and caused the loss of local government credibility. lead to the public's distrust of the local government's ability to handle public emergencies and a crisis of public trust in the local government. [9] The epidemic is fierce. Although the Wuhan Municipal Government took timely measures to deal with it, it still couldn't stand the challenges brought by the epidemic. Where there were mistakes in the initial prevention and control actions, the local people questioned the government's ability to prevent and control the epidemic, and the government Impaired credibility.

\section{REASONS FOR THE LOSS OF LOCAL GOVERNMENT CREDIBILITY IN PUBLIC EMERGENCIES}

\subsection{Local governments lack capacity to judge crisis}

Although it is difficult to predict the outbreak of the event, there will always be some signs in the early stages. If the crisis can be judged in time and measures taken to deal with it, it is possible to prevent the crisis from expanding. On December 8, 2019, an unexplained pneumonia epidemic occurred in Wuhan. On the 30th, an expert group of the National Health Commission arrived in Wuhan for investigation. Then, the Wuhan Municipal Government issued the first public notice, which stated that there were no transmissions from people and medical staff. However, the number of infected cases continued to increase, and the epidemic entered an outbreak stage, which gradually spread throughout the country and even the world. Due to the insufficient sensitivity of the Wuhan Municipal Government to detect the crisis in the early stage of the epidemic, the severity of the epidemic development was underestimated, and the best time for strong intervention was missed, which eventually led to the outbreak and widespread spread of the epidemic, causing very serious consequences and severely weakening Wuhan The credibility of the city government.

\subsection{Misbehavior of some staff members}

Public emergencies usually do not end on their own, and local governments need to take measures to respond. [10] After the epidemic broke out, the Wuhan Municipal Government moved quickly to establish a leading group for epidemic prevention and control, and adopted a variety of powerful measures to prevent the epidemic from spreading. Organize staff to enter the community for comprehensive investigations. Due to the poor sense of

\subsection{Local government did not disclose information in a timely manner}

China has entered the information age, and information is an important support for handling public emergencies. The local government's failure to disclose the relevant information of the incident in a timely manner will cause the public to distrust it to some extent and affect its credibility. At the beginning of the epidemic, the Wuhan Municipal Government reported that there were no cases of human-to-human transmission or medical staff infection, but Academician Zhong Nanshan confirmed that there was a human-to-human transmission. Mistakes in the disclosure of Wuhan Municipal Government's information have led the public to question the authenticity of its published information. With the outbreak of the epidemic, the number of confirmed diagnoses has increased rapidly. Although the Wuhan Municipal Government has reported the situation of the epidemic daily, it is still difficult to calm the public's voice of doubt. The public information errors and delays of the Wuhan Municipal Government have led to the loss of its credibility.

\section{REBUILDING THE CREDIBILITY OF LOCAL GOVERNMENTS IN PUBLIC EMERGENCIES}

\subsection{Establishing an efficient and sensitive crisis warning system}

As the main body for handling public emergencies, local governments must not only respond effectively to various public emergencies, but also prevent them from happening in advance, establish an efficient and sensitive crisis warning system, and kill the crisis in its infancy. [11] Only in this way can we improve the efficiency of local government crisis management and improve the credibility of local governments in all aspects. The key to crisis early warning lies in the establishment of an efficient information management system and the establishment of an early warning information release network covering telephone, television, radio and the Internet. Only in a scientific and standardized early warning system can the public quickly understand the real situation of the crisis, so that the public can better trust local governments and improve their credibility. 


\section{REFERENCES}

\subsection{Strengthening the sense of responsibility of administrative staff}

Improving the sense of responsibility of administrative staff is an important part of enhancing the credibility of local governments in responding to public emergencies. As the executive body of the policy, the executives' words and deeds represent the image of the government. The strength of the local government's credibility is ultimately reflected by the personal qualities and abilities of the administrative staff. The sense of responsibility and work style of the local government administrators largely determines the image of the local government and the public's trust in the local government. Therefore, local government administrators should take public interest as the starting point for action and actively implement measures to deal with public emergencies. By earning public trust in local governments through practical actions, the local government's credibility can be enhanced. At the same time, local governments must also improve and implement the administrative accountability system, clean up those cadres who abuse their powers and dereliction of duty, so as to maintain the good image of local governments and rebuild credibility.

\subsection{Establish information disclosure mechanism}

In a crisis situation, information disclosure helps the public understand the truth of the incident and avoids panic caused by blind guessing. At the same time, it also allows the public to see the positive actions of local governments and maintain a good image of local governments in the hearts of the public. At the same time, local governments should strengthen communication with the public, reduce the negative impact of public emergencies on the credibility of local governments, and reshape the credibility of local governments.

\section{CONCLUSION}

Public emergencies are an important factor affecting the credibility of local governments. In recent years, the emergence of frequent public incidents has brought challenges to the governance of local governments and affected their credibility to a certain extent. As the main body for handling public emergencies, local governments should give full play to their influence and appeal, and constantly improve the government's ability to respond to crisis events in order to reshape the credibility of local governments.
[1] Wang Xiaoyun. The construction of government credibility in public emergencies [J]. Realism, 2011 (S1): 187-189.

[2] Geng Liping. Thinking about the lack and construction of government credibility from public events [J]. Social Scientist, 2011 (07): 124-126.

[3] Ye Nanke. The Basic Connotation and Promotion Path of Government's Credibility [J]. The Masses, 2011 (11): 81-83.

[4] Meng Yi, Shu Zheng. On the Promotion of Local Government's Public Trust under the Situation of Public Crisis Management [J]. Journal of Xiangtan University (Philosophy and Social Sciences), 2013, 37 (06): 101104.

[5] Tang Tiehan. Improving the credibility of the government and building a credit government $[\mathrm{J}]$. China Administration, 2005 (03): 8-10.

[6] Hui Wang, Jin Jin, Analysis of the relationship between public crisis management and credibility, 2008.

[7] Zhou Hong, Ai Taiqiang. Reconstruction of the credibility of local governments under the management of public crisis. 2011.

[8] Wang Guohong, Ma Rui. Draining and Reshaping of Local Government's Trustworthiness__From the Perspective of Multivariate Cooperative Governance Journal of Social Science of Hunan Normal University, 2013,42 (02): 70-75.

[9] Zhao Qingwen. The construction of government credibility under the concept of public crisis management [J]. Theoretical Monthly, 2013 (12): 122125.

[10] Yang Jingxian, Lack of Government Credibility and Reshaping in Public Crisis Management, 2011.

[11] Xu Yuzhen, Sun Chaoqun. Research on the Restoration of Social Trust after Public Crisis Incidents: A Case Study of Public Health Emergencies, 2019. 